\title{
GOOD ADVICE
}

\section{Dear Reader,}

What is the job of an advisory board? It is there to provide good advice. According to Wikipedia, an advisory board is a body that advises the management of a corporation, organisation or foundation. It integrates a target group into a project in order to benefit from external expertise. The ATZ family has been making use of the advantages of an active advisory board for many years, also as a sign of its esteem for the board's members.

The meetings of the scientific-technical advisory boards of ATZ, ATZelektronik and MTZ were held in recent weeks. Once a year, heads of development at OEMs, suppliers and development service providers as well as directors of university institutes come together to adjust the guide rails of the editorial reporting in our specialist magazines, based on their experience and foresight. What were the important issues last year and what will be the most important next year? In Fulda, Sindelfingen and Stuttgart, the experts discussed those topics that will reappear in our magazines in a journalistic form. The ATZ advisory board members addressed such long-running topics as electric and hybrid powertrains, $\mathrm{CO}_{2}$ reduction and lightweight design, as well as newer subjects such as automated driving, improved aerodynamics in heavy goods vehicles through changes in length and Connected Services (inboard, offboard) and the functionality of operating concepts. If you would like to find out who the members of the ATZ advisory board are, you can find a list in the imprint on page 44 .

The advisory board also looked at the issue of standardisation of terminology. Instead of active and passive safety, the term integral safety is now used. The two departments of Calculation/ Simulation and Testing/Measuring long ago ceased working independently of each other. These individual subjects belong together conceptually, they are better covered by the common term Testing. The editorial team is grateful for such input and is happy to adopt these proposals.

In future, we would like to involve the advisory board even more. Before their next meeting, the members are being asked to name three top subjects from their perspective. The ensuing discussion will certainly produce exciting results. We need only think of today's controversial topics such as the NEDC successor, the R1234yf refrigerant or whether we use the term autonomous or automated driving. In spite of all differences in opinion, the focus at the next meeting of the advisory board in autumn 2014 should not only be on debating but also on an exchange of ideas. In the words of Samuel Taylor Coleridge: "Advice is like snow - the softer it falls, the longer it dwells upon, and the deeper in sinks into the mind." I wish you plenty of good advice - and an excellent start to the New Year 2014.

Best regards,

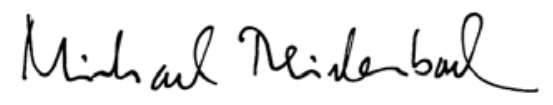

DIPL.-ING. MICHAEL REICHENBACH,

Vice-Editor in Chief

Wiesbaden, 26 November 2013

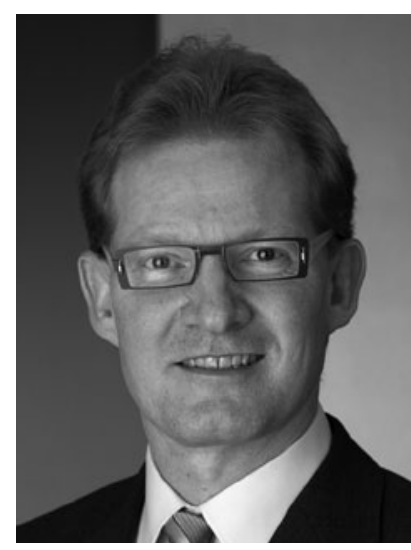

